\title{
PEMILIHAN STRATEGI PENINGKATAN DAYA SAING INDUSTRI TEKSTIL DENGAN PENDEKATAN ANP-BOCR
}

\author{
STRATEGY SELECTION TO INCREASE COMPETITIVENESS OF TEXTILE \\ INDUSTRY WITH ANP-BOCR APPROACH
}

\author{
Andi Susanto, Arief Daryanto, Bagus Sartono \\ Sekolah Bisnis Institut Pertanian Bogor, Gedung SB IPB, J1. Raya Pajajaran, Bogor 16151, Indonesia \\ Bogor 16151, Indonesia. E-mail: andi.ndhiez.susanto@gmail.com
}

Tanggal diterima: 14 Juli 2017, direvisi: 4 Oktober 2017, disetujui terbit: 2 November 2017

\begin{abstract}
ABSTRAK
Industri Tekstil dan Produk Tekstil (TPT) adalah industri yang berperan penting dalam perekonomian nasional sebagai penyumbang devisa ekspor non migas, penyerap tenaga kerja dan memenuhi kebutuhan sandang dalam negeri. Namun, perkembangan industri TPT dalam beberapa tahun terakhir mengalami penurunan daya saing yang ditandai dengan laju pertumbuhan negatif, nilai ekspor yang menurun dan berkurangnya kontribusi terhadap PDB. Penurunan kinerja ini tidak sejalan dengan perkembangan konsumsi domestik maupun dunia yang justru terus naik. Oleh sebab itu, untuk mengembalikan kinerja industri TPT diperlukan penentuan langkah strategis yang tepat. Pendekatan dengan Analytic Network Process (ANP) dengan kontrol kriteria benefits, opportunities, cost dan risks (BOCR) dipilih untuk menentukan prioritas dari langkah-langkah strategis yang ditetapkan. Hasil analisis ANP-BOCR menunjukkan bahwa strategi prioritas peningkatan daya saing industri TPT adalah perbaikan iklim usaha dan pemberian insentif dalam rangka investasi bahan baku, bahan penolong, aksesoris dan mesin/peralatan untuk skenario standar, optimistis dan pesimistis serta peningkatan ekspor dan perluasan pasar melalui kebijakan perdagangan dan kerjasama luar negeri untuk skenario realistis. Alternatif strategi yang paling rendah prioritasnya untuk semua skenario adalah peningkatan inovasi dan litbang serta kolaborasi lembaga penelitian, pemerintah, industri dan universitas serta peningkatan akses sumber modal dan penguatan dukungan pasar dan institusi keuangan. Hasil analisis rater agreement menunjukkan seluruh responden pakar memiliki kesepakatan yang tinggi terhadap prioritas strategi yang ditetapkan yang ditunjukkan dengan nilai koefisien Kendall's $W$ lebih dari 0.38 .
\end{abstract}

Kata kunci: daya saing, tekstil, ANP-BOCR

\begin{abstract}
Textile industry playing key role in Indonesian economy as foreign exchange earner of non-oil exports, massive employer sector, and supply domestic consumption. However, development of this industry in recent years decreased which is characterized by a negative growth rate, the value of exports dropping and a reduced contribution to GDP. This performance is not in line with development of domestic consumption and the world that continue to rise. Therefore, to increase competitiveness of this industry, strategic determination is required. Analytic Network Process $(A N P)$ with the control criteria of benefits, opportunities, cost and risks (BOCR) was chosen to determine the priority over the strategic measures that have been chosen. The results of analysis suggest that priority strategy to improve competitiveness of textile industry is business climate improvements and granting investment incentives in the framework of raw materials, accessories, auxiliaries and machinery/equipment for the standard scenario, optimistic and pessimistic and increase in export and market expansion through trade policy and foreign cooperation for realistic scenarios. An alternative strategy with the lowest priority over all scenarios is an increase in innovation and $R \& D$ with collaboration of research institutions, governments, industry and universities also improvement to access sources of capital and strengthening of market support and financial institutions. The results of analysis ratter agreement show that the whole of the respondent's has a high deal with defined strategy and priorities indicated by the value of the coefficient Kendall's W more than 0.38 .
\end{abstract}

Keywords: Competitiveness, textile, ANP-BOCR 


\section{PENDAHULUAN}

Industri tekstil dan produk tekstil (TPT) merupakan salah satu industri perintis dan tulang punggung industri manufaktur di Indonesia. Industri ini menjadi salah satu industri prioritas dan andalan yang akan dikembangkan sesuai dengan Peraturan Pemerintah No. 14 tahun 2015 tentang Rencana Induk Pembangunan Industri Nasional. ${ }^{1}$ Industri TPT menjadi prioritas karena peranan yang besar terhadap perekonomian nasional yaitu sebagai penyumbang devisa ekspor nonmigas, penyerap tenaga kerja dan pemenuhan kebutuhan dalam negeri. ${ }^{2,3}$

Ekspor TPT pada tahun 2015 mencapai US\$ 12,28 miliar atau $8,17 \%$ dari total ekspor industri, menyerap 2,79 juta tenaga kerja atau $17,03 \%$ dari total tenaga kerja industri manufaktur dan hasil produksinya mampu memenuhi $70 \%$ kebutuhan sandang dalam negeri. ${ }^{4}$ Komoditas TPT menempati urutan ketiga ekspor produk manufaktur dan memberikan surplus dalam neraca perdagangan serta berperan strategis dalam proses industrialisasi. ${ }^{3}$ Surplus selama 5 tahun terakhir rata-rata mencapai US\$ 4 miliar, namun di sisi lain impornya juga cenderung meningkat.

Permasalahan yang dihadapi industri TPT saat ini adalah daya saing yang mulai melemah ditandai dengan perlambatan bahkan laju pertumbuhan negatif, penurunan kinerja ekspor dan berkurangnya kontribusi terhadap PDB. Selain itu, stigma negatif dari kalangan perbankan yang mengkategorikan industri ini sebagai industri yang berisiko tinggi atau sunset industry. Permasalahan lain yang turut menyebabkan penurunan daya saing yaitu biaya energi yang mahal, infrastruktur pelabuhan yang belum kondusif, mesin-mesin pertekstilan yang sebagian besar sudah tua dan maraknya produk impor ilegal terutama dari Cina. ${ }^{5}$ Selain itu, tingginya tingkat suku bunga dan pajak, biaya energi, biaya penyusutan mesin serta ketergantungan pada mesin impor, bahan baku kapas dan pewarna tekstil, kurangnya pengembangan pasar tujuan ekspor, ketergantungan terhadap Dolar Amerika, menurunnya daya beli masyarakat, tingginya biaya pelabuhan ekspor dan krisis global yang terjadi juga turut menyebabkan penurunan daya saing pada industri TPT. ${ }^{6}$

Berdasarkan kondisi di atas diperlukan langkah-langkah strategis untuk mengatasi berbagai permasalahan yang ada sekaligus meningkatkan daya saing industri ini. Pemilihan terhadap langkahlangkah strategis yang telah ditetapkan selanjutnya dilakukan penetapan prioritasnya paling efektif dan tepat sasaran agar jumlah anggaran yang terbatas baik dari pemerintah maupun swasta dapat memberikan dampak yang lenih nyata.

\section{METODE}

Jenis dan Sumber Data

Data yang digunakan dalam penelitian ini adalah data primer yang diperoleh dari wawancara dan kuesioner yang dibagikan kepada para pakar industri TPT dari asosiasi, pakar ahli tekstil, akademisi, peneliti, dan pemerintah selaku regulator.

\section{Teknik Penentuan Pakar}

Teknik penentuan pakar dilakukan dengan menggunakan metode purposive sampling, yaitu dengan sengaja memilih pakar yang kompeten dan terlibat langsung dengan industri TPT yang terdiri dari pemerintah selaku regulator, dunia usaha yang diwakili asosiasi, praktisi atau ahli tekstil yang diwakili ikatan ahli tekstil seluruh indonesia, akademisi dari politeknik STTT dan lembaga penelitian yang diwakili Balai Besar Tekstil. Rincian daftar pakar yang menjadi narasumber ditunjukkan pada Tabel 1.

Tabel 1. Responden pakar sebagai narasumber penelitian

\begin{tabular}{llc}
\hline No & \multicolumn{1}{c}{ Narasumber } & \multicolumn{1}{c}{$\begin{array}{c}\text { Jumlah } \\
\text { Narasumber }\end{array}$} \\
\hline 1. & $\begin{array}{l}\text { Direktur Industri Tekstil, Kulit, Alas } \\
\text { Kaki dan Aneka, Kementerian }\end{array}$ & 1 \\
& $\begin{array}{l}\text { Perindustrian } \\
\text { 2. }\end{array}$ & $\begin{array}{l}\text { Ketua Umum Asosiasi Pertekstilan } \\
\text { Indonesia (API) }\end{array}$ \\
3. & $\begin{array}{l}\text { Sekretaris Jenderal Asosiasi } \\
\text { Produsen Serat dan Benang Sintetis }\end{array}$ & 1 \\
& $\begin{array}{l}\text { Indonesia (APSyFI) } \\
\text { 4. }\end{array}$ & $\begin{array}{l}\text { Ketua Wilayah Jawa Barat, Ikatan } \\
\text { Ahli Tekstil Seluruh Indonesia }\end{array}$ \\
(IKATSI) & 1 \\
5. & $\begin{array}{l}\text { Akademisi Politeknik STTT } \\
\text { K. }\end{array}$ & 1 \\
& Sepala Bidang Sarana Riset dan \\
\hline
\end{tabular}

\section{Metode Analisis dan Pengolahan Data}

Penelitian ini menggunakan metode Analytical Network Process (ANP) untuk merumuskan model strategi pengembangan industri TPT yang terbaik. Metode ini mampu merepresentasikan tingkat kepentingan berbagai pihak dengan mempertimbangkan saling keterkaitan antar kriteria dan sub kriteria yang ada. Metode ANP 
mampu memperbaiki kelemahan metode sebelumnya yaitu Analytical Hierarchy Process (AHP) yaitu kemampuan mengakomodasi keterkaitan antar kriteria atau alternatif (Saaty 2004). Keterkaitan pada metode ANP ada dua jenis yaitu keterkaitan dalam satu set elemen (inner dependence) dan keterkaitan antar elemen yang berbeda (outer dependence). Adanya keterkaitan tersebut menyebabkan metode ANP lebih kompleks dibanding metode AHP.

Tahapan pada metode ANP dijelaskan secara rinci pada Gambar 1.

1. Konstruksi Model, disusun berdasarkan literature review secara teori maupun empiris dan memberikan pertanyaan pada pakar dan praktisi TPT serta melalui indepth interview untuk mengkaji informasi secara lebih mendalam.

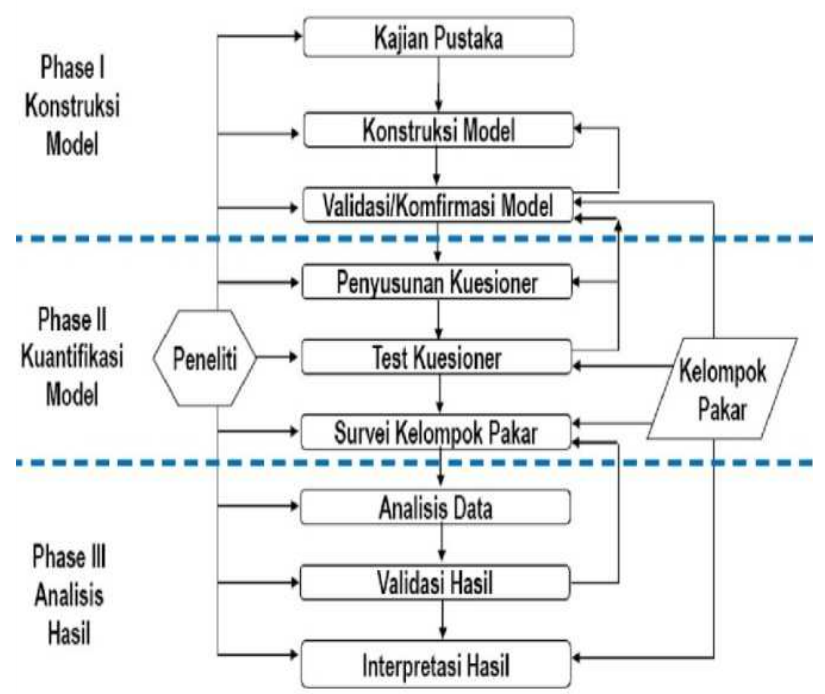

Gambar 1. Tahapan penelitian dengan ANP. ${ }^{7}$

2. Kuantifikasi Model, setelah kerangka ANP yang dirancang fix, langkah berikutnya adalah merancang kuesioner sesuai dengan kerangka ANP berupa pairwise comparison (pembandingan pasangan) antar elemen dalam cluster untuk mengetahui mana diantara keduanya yang lebih besar pengaruhnya (lebih dominan) dan seberapa besar perbedaannya melalui skala numerik 1-9. Data hasil penilaian kemudian diinput melalui peranti lunak super decision untuk diproses sehingga menghasilkan output berbentuk prioritas dan supermatriks. Hasil dari setiap responden akan diinput pada jaringan ANP tersendiri. ${ }^{8}$

3. Sintesis dan analisis

\section{a. Geometric Mean}

Untuk mengetahui hasil penilaian individu dari para responden dan menentukan hasil pendapat pada satu kelompok dilakukan penilaian dengan menghitung geometric mean. ${ }^{\mathbf{9}}$ Pertanyaan berupa perbandingan berpasangan (pairwise comparison) dari responden akan dikombinasikan sehingga membentuk suatu konsensus. Geometric mean merupakan jenis penghitungan rata-rata yang menunjukkan tendensi atau nilai tertentu dimana memiliki formula seperti dalam persamaan (1). ${ }^{8}$

$$
G M \bar{y}=\sqrt[n]{y_{1} y_{2} y_{3} y_{4} y_{5} \ldots \ldots y_{n}}
$$

dimana:

GMy = nilai geometric mean

$y_{1} y_{2} y_{3} y_{4} \ldots . . y_{n}=$ nilai yang akan di geomeankan

4. Analisis Rater Agreement

Analisis Rater agreement adalah ukuran yang menunjukkan tingkat kesesuaian (persetujuan) para responden (R1-Rn) terhadap suatu masalah dalam satu cluster. Adapun alat yang digunakan untuk mengukur rater agreement adalah Kendall's coefficient of concordance $(\mathrm{W} ; 0<\mathrm{W}<$ 1). Jika nilai pengujian $\mathrm{W}=1$, dapat disimpulkan bahwa penilaian atau pendapat dari para responden memiliki kesesuaian yang sempurna, sebaliknya jika nilai $\mathrm{W}=0$ atau semakin mendekati 0, maka menunjukkan adanya ketidaksesuian antar jawaban responden atau jawaban yang bervariasi. ${ }^{\mathbf{2}}$

Metode ANP banyak digunakan dalam penelitian tentang kebijakan, manajemen strategis dan berbagai penelitian yang berkaitan dengan pengambilan keputusan diantaranya: Wang dan Hsu (2003) menganalisis saluran yang tepat sebagai lanjutan dari metode ANP untuk kenyamanan toko di Taiwan dalam memenuhi tantangan dari kompetisi, ${ }^{10,11}$ aplikasi ANP untuk mendukung pembobotan pada perancangan sistem penilaian kinerja dan pemilihan partner maupun aliansi strategis bisnis ke depan (Poonikom et al. 2004; Chen et al. 2008; Boran dan Yavuz 2008). 12,13,14 Jumlah sampel/responden dalam ANP tidak menjadi patokan validitas. Syarat responden yang valid dalam ANP adalah bahwa mereka adalah orang-orang yang ahli di bidangnya.

Pertanyaan dalam kuesioner ANP berupa pairwise comparison (perbandingan berpasangan) antar elemen/variabel dalam cluster untuk mengetahui mana di antara keduanya yang lebih 
besar pengaruhnya (lebih dominan) dan seberapa besar perbedaannya (pada skala 1-9). Perbandingan berpasangan dilakukan berdasarkan preferensi subyektif dari pengambil keputusan dengan membandingkan tingkat kepentingan antar variabel. Perbandingan berpasangan menggunakan skala numerik 1 sampai 9 yang merupakan terjemahan dari penilaian verbal seperti pada Tabel 2 .

Tabel 2 Perbandingan skala verbal dan skala numerik. ${ }^{9}$

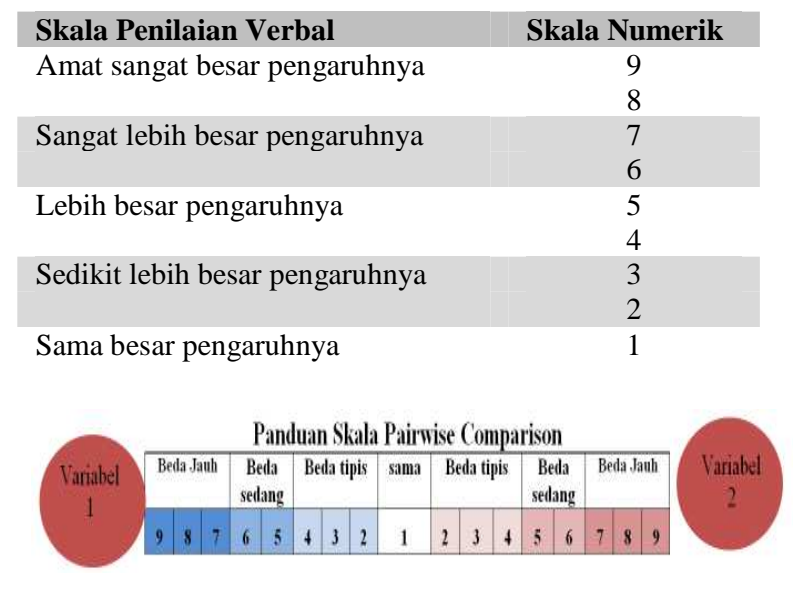

Pemilihan strategi prioritas dengan metode ANP yang digunakan pada penelitian ini menggunakan kontrol kriteria benefit, opportunity, cost, dan risk (BOCR) agar strategi yang akan diterapkan dapat teruji kehandalannya. Model pengembangan daya saing dengan ANP-BOCR pada industri ini mengacu pada beberapa penelitian sebelumnya yang dilakukan oleh Yoyo (2014), Wisena (2015), Yunia (2013) dan Rofiqi (2016). ${ }^{\mathbf{7}, 15,16,17}$

\section{HASIL DAN PEMBAHASAN}

Model strategi peningkatan daya saing industri TPT di Indonesia dan alternatif strategi yang telah ditentukan ditunjukkan dengan kerangka kerja ANPBOCR pada Gambar 2 sampai dengan Gambar 6.
Gambar 2 menunjukkan kerangka kerja ANPBOCR peningkatan daya saing industri TPT dengan 4 kontrol kriteria BOCR dengan masing-masing kontrol kriteria memiliki subnetwork yang dirinci pada

Gambar 3 sampai dengan Gambar 6.

Gambar 3 memperlihatkan lima kriteria kontrol (control criteria) yang ada dalam aspek benefits, yakni peningkatan investasi (B1), peningkatan produktivitas nasional/GDP (B2), peningkatan devisa melalui peningkatan ekspor dan peningkatan jumlah tenaga kerja (B3), peningkatan penjualan dan penerimaan pajak melalui pasar domestik (B4).

\section{GOAL}

Strategi Peningkatan Daya Saing Industri Tekstil dan Produk Tekstil di Indonesia

\begin{tabular}{c|c|}
\hline $\begin{array}{c}\text { Benefits (B) } \\
\text { Control Criteria }\end{array}$ & $\begin{array}{c}\text { Opportunities }(O) \\
\text { Control Criteria }\end{array}$ \\
\hline Subnet & Subnet \\
\hline
\end{tabular}
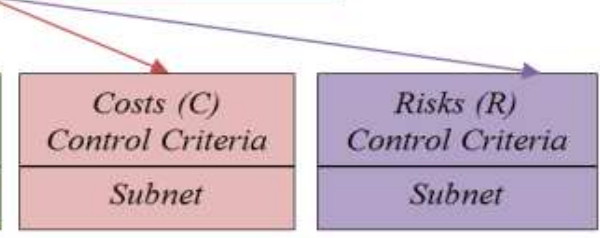
Gambar 2. Kerangka kerja ANP-BOCR

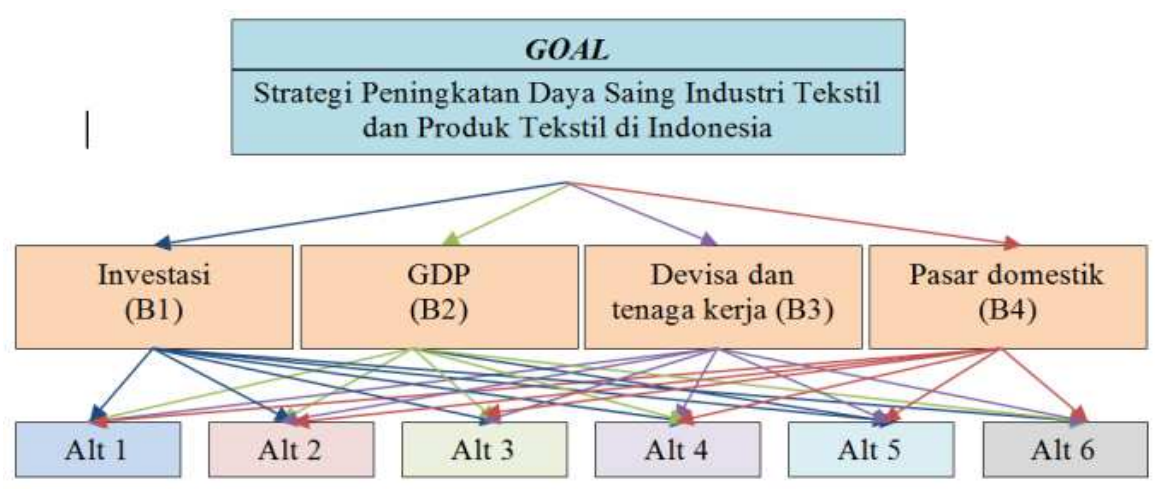

Gambar 3. Kriteria benefits pada kerangka kerja ANP-BOCR

Gambar 4 memperlihatkan empat kriteria kontrol (control criteria) yang ada dalam aspek opportunities, yakni peningkatan permintaan dunia (O1), peningkatan populasi dan konsumsi pasar domestik (O2), pengembangan dan diversifikasi produk advanced textile (O3), pengembangan industri pendukung dan industri terkait $(\mathrm{O} 4)$.

Gambar 5 memperlihatkan lima kriteria kontrol (control criteria) yang ada dalam aspek cost yaitu : peningkatan biaya insentif $(\mathrm{C} 1)$, peningkatan biaya litbang (C2), peningkatan biaya perbaikan iklim usaha (C3), peningkatan biaya pengembangan
SDM (C4) dan peningkatan biaya infrastruktur (C5).

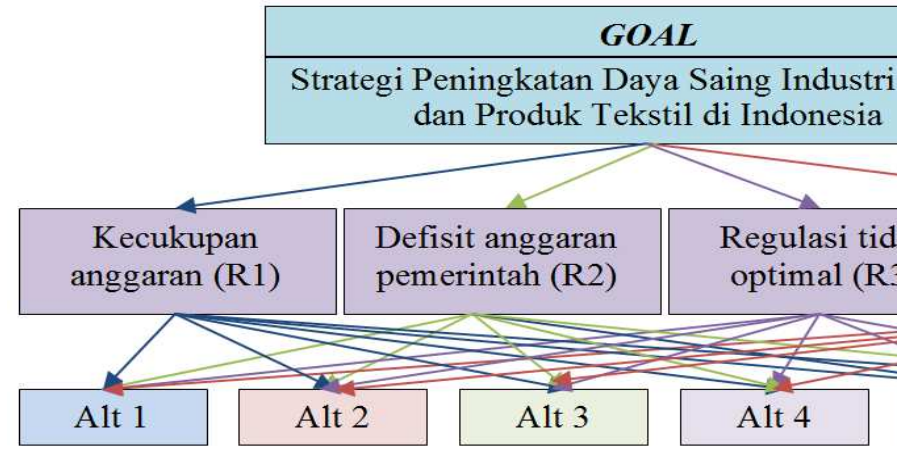

Gambar 6 memperlihatkan empat kriteria kontrol (control criteria) yang ada dalam aspek risks yaitu kecukupan anggaran pemerintah maupun swasta (R1), defisit anggaran pemerintah (R2), keterpaduan regulasi tidak optimal (R3), trade off dengan sektor lainnya terkait kerjasama dengan negara lain

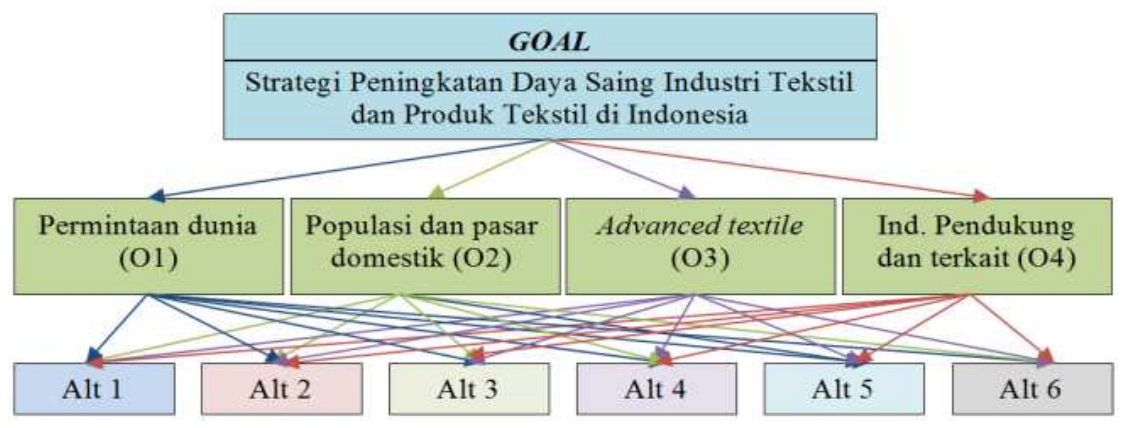

Gambar 4. Kriteria opportunies pada kerangka kerja ANP-BOCR 


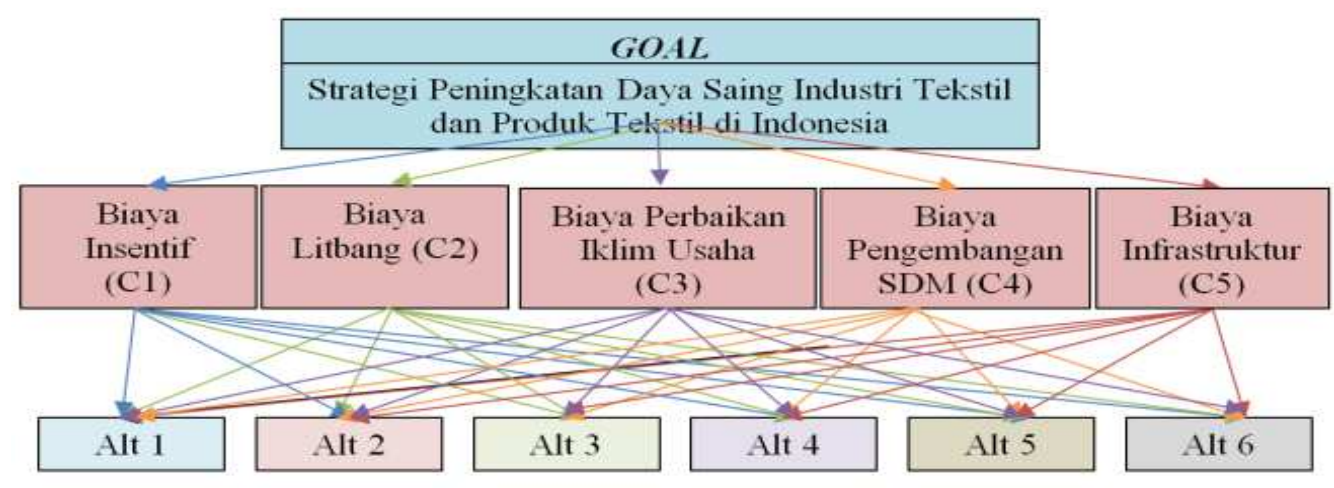

Gambar 5. Kriteria costs pada kerangka kerja ANP-BOCR

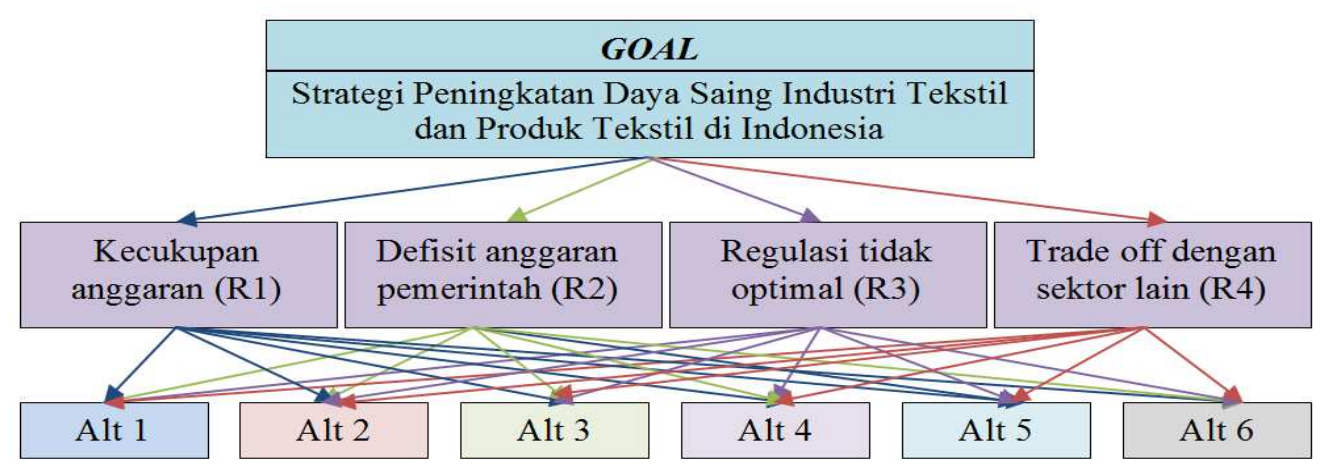

Gambar 6. Kriteria risks pada kerangka kerja ANP-BOC

Hasil sintesis model dan prioritas secara keseluruhan berdasarkan empat aspek yang menjadi kontrol kriteria pemilihan strategi melalui pendapat gabungan narasumber pakar dapat dilihat pada Error! Reference source not found.. Nilai aspek BOCR yang dinormalisasikan digunakan sebagai dasar penentuan prioritas. Aspek BOCR dengan nilai normalisasi yang lebih besar memiliki peringkat yang lebih tinggi, demikian juga sebaliknya. Hasil sintesis menunjukkan aspek manfaat (benefits) sebagai peringkat pertama memiliki nilai yang dinormalisasikan dan nilai pembatas (limiting) yang jauh lebih besar daripada aspek risiko (risks) sebagai peringkat terakhir.

Tabel 3 Urutan prioritas pada komponen BOCR

\begin{tabular}{clccc}
\hline No & Aspek & Normal & Limiting & Ranking \\
\hline 1 & Benefits & 0.525160 & 0.525161 & 1 \\
2 & Oportunity & 0.276517 & 0.276519 & 2
\end{tabular}

\begin{tabular}{lllll}
3 & Costs & 0.115590 & 0.115593 & 3 \\
4 & Risks & 0.073615 & 0.073616 & 4 \\
\hline
\end{tabular}

Hasil keluaran ANP-BOCR pada aspek BOCR menunjukkan bahwa prioritas utama dari 4 kriteria adalah aspek benefits. Hal ini menunjukkan bahwa dalam pemilihan strategi meningkatkan daya saing industri TPT di Indonesia, alternatif strategi yang memberikan keuntungan atau manfaat terbesarlah yang seharusnya dipilih. Sedangkan untuk ranking terendah adalah aspek risks. Hal ini berarti dalam pemilihan alternatif strategi, risiko yang mungkin timbul mendapatkan prioritas terendah dibandingkan aspek lainnya.

Hasil BOCR masing-masing alternatif strategi dihitung untuk memperoleh overall outcomes-nya, sehingga prioritas strategi dapat ditetapkan dalam beberapa skenario yang berbeda seperti diperlihatkan pada Tabel 4. Alternatif strategi terbaik adalah perbaikan iklim usaha dan pemberian insentif dalam rangka investasi bahan baku, bahan 
penolong, aksesoris dan mesin/ peralatan untuk skenario standar, optimistis dan pesimistis. Sedangkan, peningkatan ekspor dan perluasan pasar melalui kebijakan perdagangan dan kerjasama luar negeri untuk skenario realistis. Artinya dari empat skenario, ada tiga skenario (standar, optimistis dan pesimistis) yang merekomendasikan strategi yang sama.

Hal ini wajar, mengingat perbaikan iklim usaha diharapkan menjadi kunci masuknya investasi baik dari dalam maupun luar negeri dalam jumlah besar. Selain itu iklim usaha yang baik juga menyebabkan industri existing menjadi lebih nyaman dalam berusaha dan akan fokus pada perbaikanperbaikan faktor internal yang dirasa masih menghambat daya saing. Pemberian insentif juga diperlukan dalam rangka menggairahkan kembali industri TPT yang cenderung menurun dan menyebabkan banyak pengusaha beralih ke bisnis lain. Insentif dalam rangka menumbuhkan industri bahan baku, bahan penolong dan aksesoris juga diharapkan dapat menghemat devisa yang selama ini digunakan untuk keperluan impor bahan baku. Insentif di sektor hulu dan terkait juga diperlukan untuk menimbulkan multiplier effect yang besar bagi sektor industri turunannya. Investasi mesin peralatan juga perlu didorong insentif sebagai salah satu langkah perusahaan dalam meningkatkan efisiensi dan produktivitas perusahaan.

Alternatif strategi yang prioritasnya paling rendah untuk semua skenario adalah peningkatan inovasi dan Litbang serta kolaborasi lembaga penelitian, pemerintah, industri dan universitas serta peningkatan akses sumber modal dan penguatan dukungan pasar dan institusi keuangan. Hal tersebut disebabkan kinerja industri yang selama ini menurun perlu dilakukan perbaikan secepat mungkin sehingga peran litbang menjadi penting ketika perusahaan atau industri sudah mulai sehat dan mulai mengembangkan usahanya. Sedangkan akses sumber modal dan penguatan dukungan pasar dan institusi keuangan menjadi prioritas terendah karena kalangan perbankan yang berupaya meminimalisir risiko dengan membatasi kredit pada sektor ini.

\section{Analisis Rater Agreement Hasil ANP}

Ukuran akurasi tingkat kesepakatan para responden terhadap penentuan prioritas strategi dan kriterianya yang dipilih pada metode ANP diuji dengan menggunakan analisis rater agreement. Nilai koefisien Kendall's $W$ dapat dihitung dengan menggunakan bantuan program perangkat lunak pengolahan data statistik Minitab 16.

Rekapitulasi nilai koefisien Kendall's $W$ hasil pengolahan terhadap seluruh node (atribut) yang ada pada framework ANP strategi daya saing industri TPT disajikan pada Tabel 5. Setiap node diranking berdasarkan hasil penilaian/pendapat enam responden pakar hasil pengolahan ANP. Tabel tersebut diketahui bahwa dalam hal seluruh node (atribut) pada strategi peningkatan daya saing industri TPT menunjukkan bahwa seluruh responden memiliki kesepakatan yang tinggi yang ditunjukkan dengan nilai koefisien Kendall's W lebih dari 0.38

Tabel 4. Overall outcomes dari semua alternatif strategi

\begin{tabular}{ccccccccc}
\hline \multirow{2}{*}{$\begin{array}{c}\text { Alternatif } \\
\text { Strategi }\end{array}$} & \begin{tabular}{c} 
Benefits \\
\cline { 2 - 8 }
\end{tabular} & $\begin{array}{c}\text { Opportuniti } \\
\text { es }\end{array}$ & Costs & Risks & $\begin{array}{c}\text { Standar Optimist } \\
\text { is }\end{array}$ & Realistis & Pesimistis \\
\cline { 2 - 8 } & $\mathbf{0 , 5 2 5 1 6}$ & $\mathbf{0 , 2 7 6 5 2}$ & $\mathbf{0 , 1 1 5 5 9}$ & $\mathbf{0 , 0 7 3 6 1}$ & B/C & BO/CR & $\begin{array}{c}\text { bB+oO-cC- } \\
\text { rR }\end{array}$ & B/(CxR) \\
\hline 1 & 0,21463 & 0,17214 & 0,16462 & 0,25912 & 1,30 & 0,87 & $\mathbf{0 , 1 6}$ & 5,03 \\
2 & 0,09051 & 0,18944 & 0,19267 & 0,16186 & $\mathbf{0 , 4 7}$ & 0,55 & 0,06 & $\mathbf{2 , 9 0}$ \\
3 & 0,23786 & 0,21364 & 0,23879 & 0,15201 & 1,00 & 1,40 & 0,04 & 6,55 \\
4 & 0,16589 & 0,16395 & 0,16114 & 0,19119 & 1,03 & 0,88 & 0,07 & 5,38 \\
5 & 0,16318 & 0,16162 & 0,08950 & 0,09509 & $\mathbf{1 , 8 2}$ & $\mathbf{3 , 1 0}$ & 0,06 & $\mathbf{1 9 , 1 7}$ \\
6 & 0,07354 & 0,07525 & 0,06896 & 0,17352 & 1,07 & $\mathbf{0 , 4 6}$ & $\mathbf{0 , 0 3}$ & 6,15 \\
\hline
\end{tabular}

Keterangan :

1. Peningkatan ekspor dan perluasan pasar melalui kebijakan perdagangan dan kerjasama luar negeri

2. Peningkatan inovasi dan Litbang dan kolaborasi lembaga penelitian, pemerintah, industri dan universitas

3. Peningkatan produktivitas dan kompetensi SDM dan kolaborasi dengan lembaga pendidikan

4. Peningkatan penetrasi pasar domestik dan perlindungan dari produk impor 
5. Perbaikan iklim usaha dan pemberian insentif dalam rangka investasi bahan baku, bahan penolong, aksesoris dan mesin/peralatan

Peningkatan akses sumber modal dan penguatan dukungan pasar dan institusi

Tabel 5. Indeks keakuratan koefisien Kendall's all cluster

\begin{tabular}{lcrrc}
\hline Atribut/Cluster & $\begin{array}{l}\text { Koefisien } \\
\text { Kendall's }\end{array}$ & Chi-sq & DF & P \\
\hline All BOCR & 0.9444 & 17 & 3 & 0.0007 \\
All Element & 0.6307 & 64.33 & 17 & 0.0000 \\
BOCR & & & & \\
All Benefits & 0.4095 & 9.83 & 4 & 0.0434 \\
All Costs & 0.5954 & 14.29 & 4 & 0.0064 \\
All Opportunities & 0.3889 & 7 & 3 & 0.0719 \\
All Risks & 0.6977 & 12.56 & 3 & 0.0057 \\
\hline
\end{tabular}

\section{KESIMPULAN}

Strategi prioritas peningkatan daya saing industri TPT untuk skenario standar, optimistis dan pesimistis adalah perbaikan iklim usaha dan pemberian insentif dalam rangka investasi bahan baku, bahan penolong, aksesoris dan mesin/peralatan, sedangkan untuk skenario realistis adalah peningkatan ekspor dan perluasan pasar melalui kebijakan perdagangan dan kerjasama luar negeri. Alternatif strategi yang paling rendah prioritasnya untuk semua skenario adalah peningkatan inovasi dan Litbang serta kolaborasi lembaga penelitian, pemerintah, industri dan universitas serta peningkatan akses sumber modal dan penguatan dukungan pasar dan institusi keuangan. Hasil analisis rater agreement menunjukkan bahwa seluruh responden pakar memiliki kesepakatan yang tinggi terhadap prioritas strategi yang ditetapkan dan ditunjukkan dengan nilai koefisien Kendall's W lebih dari 0.38.

Untuk melaksanakan strategi-strategi yang disarankan, maka diperlukan kerjasama antara pemerintah, asosiasi, perguruan tinggi, lembaga penelitian dan pengembangan serta pelaku usaha untuk bersama-sama dan saling bersinergi dalam pelaksanaan strategi tersebut.

\section{PUSTAKA}

1. Kemenperin. Rencana Induk Pembangunan Industri Nasional 2015 - 2035 (2015).

2. Kemenperin. Daya saing industri TPT Indonesia terbebani biaya listrik. Media Industri, 4(11): 30-31 (2014).
3. Fajri, T., Triyowati, H. Peranan sektor industri tekstil dan produk tekstil (TPT) terhadap perekonomian Indonesia : Analisis Input-Output. Jurnal Ekonomi Pembangunan, 1(1):37-58 (2014).

4. Kemenperin. Facts and Figures Industri Tekstil dan Produk Tekstil 2015 (2016).

5. Miranti, E. Mencermati kinerja tekstil indonesia: antara potensi dan peluang. Economic Review, 209:1-10 (2007).

6. Prasetyo, E. Kesiapan industri tekstil dalam mendukung poros maritim dan peningkatan daya saing. Universitas Negeri Semarang, 978-979 (2015).

7. Wisena, B.A. Analisis strategi daya saing industri kelapa sawit yang berkelanjutan. Doctoral Disertation. Sekolah Pascasarjana, Institut Pertanian Bogor di Bogor, Indonesia. (2015).

8. Ascarya. Analytic Network Process (ANP): Pendekatan Baru Studi Kualitatif. Seminar Intern Program Magister Akuntansi Fakultas Ekonomi di Universitas Trisakti (2005).

9. Saaty, T.L. Decision making with the analytic hierarchy process. International Journal Services Sciences, 1(1):83-98 (2008).

10. Wang, B.J., Hsu, M.Y. Application of the analytical network process to select a channel type for e-convenient chain Stores-ANP. An International Journal, 25(12):236-278 (2003).

11. Vanany, I. Aplikasi Analytic Network Process (ANP) pada perancangan sistem pengukuran kinerja (studi kasus pada PT. X). Jurnal Teknik Industri, 5(1):50-62 (2003).

12. Saaty, T.L. Decision making-the analytic hierarchy and network processes (AHP/ANP). Journal of Systems Science and Systems Engineering, 13(1):1-35 (2004).

13. Boran, S., Göztepe, K., Yavuz, E. A Study on election of personnel based on performance measurement by using Analytic Network Process (ANP). International Journal of 
Pemilihan Strategi Peningkatan Daya Saing Industri Tekstil dengan Pendekatan ANP-BOC (Andi Susanto, dkk.)

Computer Science and Network Security, 8(4):333-338 (2008).

14. Chen, S.H., Lee, H.T., Wu, Y.F. Applying ANP approach to partner selection for strategic alliance. Journal of Management Decision, 46(3):449-465 (2008).

15. Rofiqi, D.M. Strategi percepatan pengembangan industri turunan minyak sawit mentah (MSM) di Indonesia. Master Thesis. Sekolah Pascasarjana, Institut Pertanian Bogor di Bogor, Indonesia (2016).
16. Yoyo, T. Strategi pengembangan daya saing industri asam lemak dan alkohol lemak berbasis minyak kelapa sawit di Indonesia. Doctoral Disertation. Sekolah Pascasarjana, Institut Pertanian Bogor di Bogor, Indonesia (2014).

17. Yunia, C. Model strategi pengembangan dan pengelolaan taman nasional laut yang berkelanjutan. Doctoral Disertation. Sekolah Pascasarjana, Institut Pertanian Bogor di Bogor, Indonesia (2013). 